INVESTIGACIÓN

Recibido: 16/03/2021 --- Aceptado: 16/03/2021 --- Publicado: 24/05/2021

\title{
LA REPRESENTACIÓN DE LA PANDEMIA DEL COVID-19 EN LOS DOODLES DE GOOGLE
}

\section{The representation of the covid-19 pandemic in google doodles}

Inmaculada Berlanga-Fernández: Universidad Internacional de la Rioja. España.

inmaculada.berlanga@unir.net

88 Marta Sánchez-Esparza: Universidad Rey Juan Carlos. España. marta.sanchez@urjc.es

\section{Cómo citar el artículo:}

Berlanga-Fernández, I. y Sánchez-Esparza, M. (2021). La representación de la pandemia del COVID-19 en los Doodles de Google. Vivat Academia. Revista de Comunicación, 154, 79-94. http://doi.org/10.15178/va.2021.154.e1338

http://www.vivatacademia.net/index.php/vivat/article/view/1338

\section{RESUMEN}

El presente trabajo estudia los Doodles de la página principal de la plataforma de búsqueda de Google como un ejemplo de marketing sensorial y experiencial. Se centra concretamente en los Doodles publicados durante el confinamiento por el covid-19 que hicieron referencia de alguna forma a la pandemia. El objetivo es mostrar cómo Google con esta estrategia recupera las tres funciones tradicionales de los medios de comunicación masivos: formar, informar y entretener. Se ha llevado a cabo un estudio cualitativo a través de una herramienta de evaluación y medida de las comunicaciones experienciales de marca que utilizan medios digitales diseñada a partir de la Matriz Experiencial de Schmitt. El método combina la observación y sistematización de los Módulos Experienciales y el examen de los Expros o diferentes Proveedores de Experiencias que se utilizan para dar forma a cada acción experiencial, y que en el caso de los Doodles son ocho: imágenes, textos, animaciones, sonidos, herramientas de interactuación, herramientas de compartición, herramientas para ampliar información y herramientas de intercambio de información o producción colectiva. Los resultados muestran una estrategia enfocada en dos direcciones: concienciar a la ciudadanía y

\footnotetext{
${ }^{1}$ Inmaculada Berlanga Fernández: Profesora Titular Área de Comunicación Audiovisual. Docente en el Máster de Neuromarketing de la Facultad de Humanidades y Ciencias Sociales de la UNIR. Investigadora Principal de PROCOMM (Prospectivas en Comunicación Multimedia).
} 
mostrar agradecimiento a determinados sectores de la población. A pesar de simplificarse la intensidad de la estimulación sensorial de los Doodles con respecto a otros momentos estudiados, se afirma que pueden considerarse una experiencia donde se comparten sentimientos, sensaciones, pensamientos y actuaciones con la audiencia, y que además se hace de forma pedagógica, lúdica y emotiva.

PALABRAS CLAVE: Marketing experiencial - Marketing sensorial - Comunicación Google - Doodle - Covid-19 - Marca.

\section{ABSTRACT}

This paper studies the Doodles on the homepage of the Google search platform as an example of experiential marketing. Specifically, it focuses on the Doodles published during the confinement by covid-19 referring to the pandemic. The goal is to show how Google with this strategy recovers the three traditional functions of mass media: to train, to inform and to entertain. A qualitative study has been carried out through a tool for evaluating and measuring branded experiential communications using digital media designed from the Schmitt Experiential Matrix. The method combines the observation and systematization of the Experiential Modules and the examination of the Expros or different Experience Providers that are used to shape each experiential action. In the case of the Doodles, there are eight of them: images, texts, animations, sounds, interaction tools, sharing tools, and information exchange or collective production tools. The results show a strategy focused on two directions: to raise awareness and to show recognition to particular sectors of the population. Despite simplifying the intensity of the Doodles' sensory stimulation with respect to other times, they can be considered an experience where feelings, sensations, thoughts and performances are shared with the audience, and that it is also done in a pedagogical, playful and emotional way.

KEYWORDS: Experiential Marketing - Sensory Marketing - Communication Google - Doodle - Covid-19 - Brand.

Agradecimientos: Este trabajo se enmarca en el grupo de investigación PROCOMM (Prospectivas en Comunicación Multimedia) financiado por UnirResearch.

\section{INTRODUCCIÓN}

\subsection{El marketing sensorial y experiencial}

En las últimas décadas las marcas se han lanzado a elaborar estrategias de marketing basadas en la creación de experiencias a través de los sentidos, buscando ofrecer a los consumidores un valor diferencial. La mayoría de los productos son técnicamente similares, y el diseño de experiencias de compra placenteras trata de hacer de la relación entre la marca y el cliente algo único, otorgando a las empresas una ventaja competitiva, según indican autores como Singhal y Khare (2017). 
Teóricos como Max Lenderman (2006) subrayan que el marketing experiencial está cambiando a las propias marcas, y ven el origen de esta tendencia en la propia demanda de los consumidores, una demanda que ha ido dejando obsoletas otras estrategias como la bajada de precios o las promociones.

Se acabó la primacía de la marca en el marketing. Los gerentes de marca están perdiendo el control sobre esas marcas ante una base de consumidores proactiva y empoderada. En lugar de una economía de consumo en la que el éxito se determina en gran parte por el nombre, ahora está determinado por la 'performance'. El elemento de la 'performance' del producto es un componente clave para las campañas de marketing experiencial de hoy (Lenderman, 2006, p.3).

Berlanga, Galmés y Repiso (2016) sitúan a Toffler (1971) como el primer autor que percibió el comienzo de esta nueva corriente, que iría tomando forma en años sucesivos, hasta formar parte fundamental de las estrategias de las principales empresas. Poco a poco se irían desarrollando y divulgando propuestas sobre cómo apelar y satisfacer a los consumidores de modo emocional y racional, empleando para ello los cinco sentidos. El marketing sensorial conforma hoy en día una de las bases más influyentes dentro de las estrategias de atracción del consumidor, lo cual la convierte en una estrategia de diferenciación debido a que las empresas tendrán que enfocarse en los productos, la marca, los envases y los espacios no solo desde la comunicación visual e información, sino desde la creación de sensaciones que estimulen los sentidos de los consumidores para que así se identifiquen con los aromas, los sonidos y ambientes de los productos o servicios (Alistair, 2017).

Para validar la eficacia de este marketing de experiencias, el profesor Schmitt (2006), de la Universidad de Columbia, elaboró un modelo de gestión compuesto de varios módulos estratégicos experienciales basados en los sentidos, los sentimientos, los pensamientos, las acciones y la identificación de los públicos. El modelo también incluye una serie de proveedores de experiencias, que darán forma a los estímulos sensoriales hasta convertirlos en un acontecimiento significativo para el cliente (Berlanga, et al., 2016).

Cabe decir que al igual que ha ocurrido en otros terrenos, el marketing sensorial y experiencial se ha visto transformado por la irrupción de la tecnología, y son muchas las marcas que han descubierto el poder de las herramientas tecnológicas como estímulo sensorial para el consumidor (Medina y Quispe, 2019). En este sentido cobran especial relieve las herramientas que propician el impacto en el consumidor a través de la vista, pues, según estos autores, el 90\% de la información que procesa el cerebro es visual.

\subsection{Google como marca generadora de experiencias}

Google fue fundada en septiembre de 1998 por dos estudiantes de doctorado de la Universidad de Stanford: Sergey Brin y Larry Page. Aunque la idea inicial era crear un 
motor de búsqueda para los estudiantes y profesores de esa universidad, juntos acabaron fundando una empresa revolucionaria (Romero et al., 2018).

Lo que Brin y Page lograron fue programar un algoritmo de búsqueda de información en internet mucho más preciso que el de otros buscadores de la época, como Altavista, acabando por dominar el acceso a la información mundial.

Los responsables de la compañía, de hecho, formularon así la misión de la empresa, que figura actualmente en su web corporativa: organizar la información del mundo para que todos puedan acceder a ella y usarla. Ligada a esta misión, la visión de Google es lograr ser el motor de búsqueda más importante a nivel mundial. La compañía tecnológica, de hecho, lograría convertirse en pocos años en la principal aspiradora de datos digitales del mundo (National Geographic, 2012), y los numerosos productos y herramientas que ha ido lanzando han cambiado los hábitos de consumo de información de millones de personas. Autores como Vise y Malseed (2006) se refieren a la importancia del cambio cultural generado por Google:

Ningún otro invento ha dado tanto poder a la gente y ha transformado tan profundamente el acceso a la información como Google, desde que Gutenberg inventó la imprenta moderna hace quinientos años, haciendo asequibles y poniendo a disposición de las masas libros y publicaciones científicas (Vise y Malseed, 2006, p. 21).

Los productos y herramientas que Google no solo han influido en el consumo de la información, sino que, además, han convertido en experiencias novedosas y participativas el aprendizaje y el trabajo en equipo (Google Docs, Google Drive), la visualización de mapas, los viajes y el ocio (Google Maps, Google Earth, Street View, Google Trips, Waze), la divulgación del conocimiento científico (Google Scholar), los idiomas (Google Translator), la lectura y consulta de libros (Google Books) y películas (Google Play), el consumo de vídeos y su uso con fines didácticos o recreativos (Youtube), las videoconferencias (Google Meet), la organización del trabajo (Google Calendar, Google Sheets, Keep, Suite), la investigación y la elaboración de encuestas (Google Forms), la telefonía (Android, Pixel), el marketing y la publicidad (Adwords, Analytics, Trends), las compras (Google Pay, Google Shopping) o la mensajería (Gmail), entre otros ejemplos.

Google no solo lanza herramientas útiles que vienen a cubrir determinadas necesidades, sino que las convierte en experiencias nuevas y sorprendentes para el usuario. Y los Doodles (garabatos) son un ejemplo en el que se sintetiza toda una filosofía corporativa. Se trata de alteraciones del logotipo de Google en la página principal del buscador mediante ilustraciones y/o animaciones que se dirigen a conmemorar determinadas fechas o aniversarios, o a celebrar personas o logros.

\subsection{El origen de los Doodles}

Los Doodles nacieron de forma espontánea, según el testimonio de Isabel Salazar, la responsable de los Doodles en España, y poco a poco se fueron convirtiendo en una 
práctica habitual basada en jugar con el logotipo de la marca (Berlanga et al., 2016). El primer Doodle se remonta a 1998, y lo diseñaron los propios fundadores de Google, modificando el logotipo para notificar a los usuarios que se encontraban fuera de la oficina.

En la actualidad, un equipo de varias decenas de personas se dedica en exclusiva a publicar casi a diario una imagen en algún lugar del mundo relacionada con ese país, y los Doodles han evolucionado en complejidad. Es el departamento de marketing de cada país el que transmite a los diseñadores de Doodles o doodelers lo que se quiere conmemorar para que puedan trabajar en el diseño atendiendo al contexto local (Berlanga et al., 2016).

El responsable del equipo de diseñadores de Doodles para Google, Ryan Germick, entrevistado por la emisora de televisión DW, recordaba que "al principio todos los Doodles tenían un aspecto similar: líneas trazadas con colores básicos. A lo largo de los años nos dimos cuenta de que un Doodle podía dar más de sí, que podía emplearse una foto, un comic o un cuadro" (DW en Español, 2012). Según Germick, se buscan motivos sencillos y divertidos.

La diseñadora Jennifer Hom, miembro del equipo de doodleres, explicaba en la misma emisora que en cada Doodle trata de crear algo representativo de la cultura de la empresa: algo alegre y artístico, con lo que se logre "hacer felices a nuestros usuarios". Se trata de trabajos efímeros, pues sólo serán exhibidos durante 24 horas, y que en ese espacio de proponen generar "el efecto sorpresa", según Hom.

Los Doodles son acciones artísticas que suponen una experiencia de contacto visual del usuario con ciertas efemérides, con los problemas del mundo en el que vive, las causas o los logros de la humanidad, y que le vinculan como individuo a la colectividad y le sacan del aburrimiento.

Los Doodles son por tanto experiencias sensoriales que generan una conexión emocional o engagement entre la marca y los usuarios, y que pueden ser analizados como acciones de marketing experiencial. Berlanga, Galmés y Repiso ya elaboraron en 2016 un análisis de los Doodles como ejemplo de acciones experienciales de marca, empleado para ello un método basado en el modelo de módulos de Schmitt. En dicho estudio, los autores concluyeron que los Doodles son experiencias holísticas, y que en todos ellos pueden encontrarse componentes retóricos. Los Doodles que incorporan imágenes, movimiento y sonido son los más sensoriales y emocionales, pero también los que poseen mayor riqueza en su potencial intelectual.

\subsection{La pandemia como contexto comunicativo}

Puesto que nuestro objeto de estudio aparece como una experiencia comunicativa marcada por una circunstancia inusitada -situación de pandemia- nos parece oportuno dedicar un epígrafe que contextualice el fenómeno. La crisis sanitaria global generada por la aparición del virus de la Covid-19 a comienzos de 2020 es la peor que el mundo

Vivat Academia. Revista de Comunicación. 2021, nº 154, 79-94 
ha vivido desde hace al menos dos siglos, afectando a 185 países de los cinco continentes. La pandemia ha trastocado el funcionamiento de todos los sectores sociales, desde la salud, la economía, la educación, el transporte a la comunicación, la cultura y los servicios (Gil et al., 2020).

En los primeros meses de expansión de la enfermedad, y con numerosos países en situación de confinamiento, el consumo de información se disparó, especialmente a través de televisión y de medios digitales, debido a la incertidumbre generada por la situación de crisis sanitaria y al encierro obligado de los ciudadanos en sus hogares. Por ello autores como Gil, Gómez y Almansa señalan que esta pandemia podría considerarse como "la más mediática hasta la fecha, llegando incluso a generar un contexto de sobreexposición informativa" (2020, p. 123).

Las encuestas elaboradas desde la Asociación de Investigación en Medios de Comunicación revelan por ejemplo que durante el primer mes de confinamiento en España se incrementó un 27,7\% el número de usuarios que visitaron diarios digitales. Estos diarios recibieron un $45 \%$ más de páginas vistas y aumentaron su tráfico un $100 \%$ (Montaña et al., 2020).

Los lectores cambiaron además sus hábitos de lectura, pues un 35\% de los encuestados dijo haber empezado a leer otras cabeceras, aparte de la publicación acostumbrada. Un $17,9 \%$ de los encuestados se suscribieron además a una o varias plataformas OTT, según los informes de la AIMC.

La audiencia digital de la radio online creció un 112\%, y la televisión online en directo sumó un 93\% de usuarios únicos. La televisión se ha convertido durante las sucesivas olas de la pandemia en la fuente principal de entretenimiento e información. De hecho, a medida que fue avanzando el alcance de la enfermedad, los usuarios escogieron mayoritariamente para mantenerse informados la televisión, los comunicados oficiales y la prensa en línea, frente a otras opciones menos tradicionales como internet o las redes sociales (Montaña et al., 2020).

En este contexto resulta llamativo el crecimiento de los programas tipo infoshows dentro de la programación de las televisiones, por encima de los informativos tradicionales. Autores como Montaña, Ollé y Lavilla (2020) lo achacan a la necesidad de la población, en momentos de crisis o catástrofes, de combinar estar informados con el humor y el entretenimiento, dos cualidades que han sido buscadas activamente por los generadores de contenidos.

\section{OBJETIVOS}

Este artículo se propone analizar los Doodles de Google como claro ejemplo de marketing sensorial y experiencial, en concreto los Doodles publicados durante el confinamiento en España por el covid-19 que hicieron referencia de alguna forma a la pandemia; y a su vez mostrar cómo Google, con esta estrategia, recupera las tres 
funciones tradicionales de los medios de comunicación masivos: formar, informar y entretener.

\section{METODOLOGÍA}

La selección de la muestra se realizó a través del buscador de Doodles (https://www.google.com/doodles) que ofrece la web de esta marca. Fueron 25 los Doodles que hicieron referencia a la pandemia durante los meses del confinamiento. Se añadió a la muestra dos más que se repitieron en el mes de agosto. Se ha utilizado el método propuesto por Berlanga, Galmés y Repiso (2016) para evaluar, estudiar y medir comunicaciones experienciales de marca en medios digitales. Se trata de una herramienta que combina la observación y sistematización de los Módulos Experienciales Estratégicos de Schmitt a través de una aproximación de carácter numérico.

Se parte de que los Doodles utilizan para dar forma a cada acción experiencial ciertos proveedores de experiencias: imágenes, textos, animaciones, sonidos, herramientas, de interactuación, herramientas para compartir, herramientas para ampliar información y herramientas de intercambio de información o producción colectiva. Estos proveedores de experiencias conforman los cinco módulos que incluye la ficha de análisis de cada uno de los Doodles, y que delimitarán si una experiencia se califica como un híbrido experiencial o como una experiencia holística: módulo de sentimientos, de emociones, de pensamiento, de actuaciones y de relaciones. Así, para evaluar la representatividad del Módulo sensorial se ha tenido en cuenta qué sentidos se podrían estimular a través de la imagen y el sonido. En el Módulo de emociones se revisa el recurso a las figuras retóricas que suscitan emoción en los usuarios. El Módulo de actuaciones mide las posibilidades de interactuar y participar que se ofrece al usuario. El Módulo de representatividad evalúa la capacidad para despertar el interés y ampliar el conocimiento del usuario. Finalmente, en el Módulo de relaciones se analiza el nivel de estimulación para relacionarse con otros usuarios e incluso para participar en una obra colectiva. El dato numérico atribuible a cada uno de ellos permite alcanzar la cifra máxima de 500. Cuanto más se aproxime a esta cifra, la experiencia analizada podrá calificarse como experiencia holística. Si simplemente combina dos o más módulos tendremos un híbrido experiencial (Schmitt, 2010; Schmitt et al., 2015). Se adjunta la ficha de análisis.

\section{Parámetros de medición de Módulos Experienciales Estratégicos}

Representatividad del Módulo de sensaciones (0-100):

- $\quad$ sin estimulación sensorial (0)

- estimulación sensorial visual a partir de imágenes estáticas (25)

- estimulación sensorial visual a partir de imágenes con movimiento (50)

- estimulación sensorial visual y auditiva a partir de imágenes con movimiento y sonido (75)

- estimulación sensorial visual y auditiva a partir de filmaciones audiovisuales (100)

Representatividad del Módulo de emociones (0-100):

- nivel emocional a través de menos de 5 figuras retóricas (0)

- nivel emocional a través de entre 5 - 10 figuras retóricas (25)

Vivat Academia. Revista de Comunicación. 2021, no 154, 79-94 
- nivel emocional a través de 10-25 figuras (50)

- nivel emocional a través de 25-50 figuras retóricas (75)

- nivel emocional a través de más de 50 figuras retóricas (100)

Representatividad del Módulo de pensamientos (0-100):

- no hay posibilidad de adquirir conocimiento nuevo (0)

- se incluye algo de información que pueda aportar un nivel básico de conocimiento o que despierte un interés básico sobre un tema (25)

- se incluye cierta información que pueda aportar un nivel medio de conocimiento o que despierte un interés medio sobre un tema (50)

- se incluye bastante información que pueda aportar un nivel elevado de conocimiento o que despierte un interés superior sobre un tema (75)

- se incluye una información rica que puede aportar un nivel muy alto de conocimientos nuevos o que puede despertar mucho interés sobre un tema (100)

Representatividad del módulo de actuaciones (0-100):

- $\quad$ sin posibilidad de actuación (0)

- posibilidad de interactuar para ampliar información o compartir el contenido en redes sociales (25)

- posibilidades de interactuación básica (pasar imágenes hacia adelante y hacia atrás o interactuar sobre las imágenes o los sonidos) obteniendo una respuesta simple (50)

- posibilidades de interactuación alta obteniendo un resultado complejo que desaparece una vez realizado $(75)$

- posibilidad de interactuación alta obteniendo un resultado complejo que puede ser guardado o compartido (100)

Representatividad del Módulo de relaciones (0-100):

- ninguna posibilidad para compartir (0)

- posibilidad de compartir en redes sociales de forma fácil (25)

- posibilidad de compartir algo con un comentario personal de forma automática (50)

- posibilidad de compartir algo realizado por uno mismo (75)

- posibilidad de realizar algo de forma colectiva (100)

Figura 1: Parámetros de medición de Módulos Experienciales Estratégicos Fuente: elaboración propia a partir de Berlanga, Galmés y Repiso (2016)

\section{RESULTADOS}

El confinamiento en España se decretó el 13 de marzo de 2020 y terminó el 21 de junio de 2020 fecha en la que finalizó la última prórroga del estado de alarma, y se pasó a lo que se llamó "nueva normalidad". Durante ese periodo, Google publica 25 Doodles con referencia a la pandemia, el último el 8 de mayo. En el mes de agosto dedica además dos días a recordar con un Doodle la necesidad de usar mascarilla.

\section{Doodles sobre la pandemia publicados durante el confinamiento en España 2020}

\begin{tabular}{|c|c|c|}
\hline Fecha & Título Doodle & Enlace web \\
\hline $\begin{array}{l}20 \text {-mar- } \\
20\end{array}$ & $\begin{array}{l}\text { Homenaje a Ignaz Semmelweis y al } \\
\text { lavado de manos }\end{array}$ & $\begin{array}{l}\text { https://www.google.com/Doodles/recogn } \\
\text { izing-ignaz-semmelweis-and-handwashing }\end{array}$ \\
\hline 4-abr-20 & Quédate en casa. Salva vidas & $\begin{array}{l}\text { https://www.google.com/Doodles/stay- } \\
\text { home-save-lives }\end{array}$ \\
\hline 6-abr-20 & $\begin{array}{l}\text { Gracias a los trabajadores de la } \\
\text { sanidad pública y a los investigadores } \\
\text { de la comunidad científica }\end{array}$ & $\begin{array}{l}\text { https://www.google.com/Doodles/thank- } \\
\text { you-public-health-workers-and-to- } \\
\text { researchers-in-the-scie100ntific-community }\end{array}$ \\
\hline
\end{tabular}

Vivat Academia. Revista de Comunicación. 2021, nº 154, 79-94 


\begin{tabular}{|c|c|c|}
\hline 7-abr-20 & Gracias a los profesionales sanitarios & $\begin{array}{l}\text { https://www.google.com/Doodles/thank- } \\
\text { you-doctors-nurses-and-medical-workers }\end{array}$ \\
\hline 8-abr-20 & $\begin{array}{l}\text { Gracias a los trabajadores de los } \\
\text { servicios de emergencias }\end{array}$ & $\begin{array}{l}\text { https://www.google.com/Doodles/thank- } \\
\text { you-emergency-services-workers }\end{array}$ \\
\hline 9-abr-20 & $\begin{array}{l}\text { Gracias al personal de limpieza y } \\
\text { recogida de residuos }\end{array}$ & $\begin{array}{l}\text { https:// www.google.com/Doodles/thank- } \\
\text { you-custodial-and-sanitation-workers }\end{array}$ \\
\hline $\begin{array}{l}10-a b r- \\
20\end{array}$ & $\begin{array}{l}\text { Gracias a los trabajadores del campo y } \\
\text { agricultores }\end{array}$ & $\begin{array}{l}\text { https://www.google.com/Doodles/thank- } \\
\text { you-farmworkers-and-farmers }\end{array}$ \\
\hline $\begin{array}{l}\text { 13-abr- } \\
20\end{array}$ & $\begin{array}{l}\text { Gracias a los trabajadores de las } \\
\text { tiendas de alimentación }\end{array}$ & $\begin{array}{l}\text { https://www.google.com/Doodles/thank- } \\
\text { you-grocery-workers }\end{array}$ \\
\hline $\begin{array}{l}\text { 14-abr- } \\
20\end{array}$ & $\begin{array}{l}\text { Gracias a los profesionales del } \\
\text { transporte público }\end{array}$ & $\begin{array}{l}\text { https://www.google.com/Doodles/thank- } \\
\text { you-public-transportation-workers }\end{array}$ \\
\hline $\begin{array}{l}15-a b r- \\
20\end{array}$ & $\begin{array}{l}\text { Gracias a los profesionales de servicios } \\
\text { de paquetería, envíos y entregas }\end{array}$ & $\begin{array}{l}\text { https://www.google.com/Doodles/thank- } \\
\text { you-packaging-shipping-and-delivery- } \\
\text { workers }\end{array}$ \\
\hline $\begin{array}{l}16-a b r- \\
20\end{array}$ & $\begin{array}{l}\text { Gracias a los profesionales del sector } \\
\text { alimentario }\end{array}$ & $\begin{array}{l}\text { https://www.google.com/Doodles/thank- } \\
\text { you-food-service-workers }\end{array}$ \\
\hline $\begin{array}{l}17 \text {-abr- } \\
20\end{array}$ & $\begin{array}{l}\text { Gracias a docentes y profesionales de } \\
\text { guarderías }\end{array}$ & $\begin{array}{l}\text { https:// www.google.com/Doodles/thank- } \\
\text { you-teachers-and-childcare-workers }\end{array}$ \\
\hline $\begin{array}{l}18-a b r- \\
20\end{array}$ & $\begin{array}{l}\text { Gracias a quienes colaboran en la } \\
\text { lucha contra el coronavirus }\end{array}$ & $\begin{array}{l}\text { https://www.google.com/Doodles/thank- } \\
\text { you-coronavirus-helpers }\end{array}$ \\
\hline $\begin{array}{l}25-a b r- \\
20\end{array}$ & $\begin{array}{l}\text { Gracias a quienes colaboran en la } \\
\text { lucha contra el coronavirus }\end{array}$ & $\begin{array}{l}\text { https://www.google.com/Doodles/thank- } \\
\text { you-coronavirus-helpers-april-25-26 }\end{array}$ \\
\hline $\begin{array}{l}26-a b r- \\
20\end{array}$ & $\begin{array}{l}\text { Gracias a quienes colaboran en la } \\
\text { lucha contra el coronavirus }\end{array}$ & $\begin{array}{l}\text { https://www.google.com/Doodles/thank- } \\
\text { you-coronavirus-helpers-april-25-26 }\end{array}$ \\
\hline $\begin{array}{l}27-a b r- \\
20\end{array}$ & $\begin{array}{l}\text { Quédate en casa y juega con anteriores } \\
\text { Doodles populares de Google: } \\
\text { Programación (2017) }\end{array}$ & $\begin{array}{l}\text { https:// www.google.com/Doodles/stay- } \\
\text { and-play-at-home-with-popular-past- } \\
\text { google-Doodles-coding-2017 }\end{array}$ \\
\hline $\begin{array}{l}28-a b r- \\
20\end{array}$ & $\begin{array}{l}\text { Quédate en casa y juega con anteriores } \\
\text { Doodles populares de Google: Críquet } \\
\text { (2017) }\end{array}$ & $\begin{array}{l}\text { https://www.google.com/Doodles/stay- } \\
\text { and-play-at-home-with-popular-past- } \\
\text { google-Doodles-cricket-2017 }\end{array}$ \\
\hline $\begin{array}{l}29 \text {-abr- } \\
20\end{array}$ & $\begin{array}{l}\text { Quédate en casa y juega con anteriores } \\
\text { Doodles populares de Google: } \\
\text { Fischinger (2017) }\end{array}$ & $\begin{array}{l}\text { https:// www.google.com/Doodles/stay- } \\
\text { and-play-at-home-with-popular-past- } \\
\text { google-Doodles-fischinger-2017 }\end{array}$ \\
\hline $\begin{array}{l}30 \text {-abr- } \\
20\end{array}$ & $\begin{array}{l}\text { Quédate en casa y juega con anteriores } \\
\text { Doodles populares de Google: } \\
\text { Rockmore (2016) }\end{array}$ & $\begin{array}{l}\text { https://www.google.com/Doodles/stay- } \\
\text { and-play-at-home-with-popular-past- } \\
\text { google-Doodles-rockmore-2016 }\end{array}$ \\
\hline $\begin{array}{l}\text { 1-may- } \\
20\end{array}$ & $\begin{array}{l}\text { Quédate en casa y juega con anteriores } \\
\text { Doodles populares de Google: } \\
\text { Gnomos de jardín (2018) }\end{array}$ & $\begin{array}{l}\text { https://www.google.com/Doodles/stay- } \\
\text { and-play-at-home-with-popular-past- } \\
\text { google-Doodles-garden-gnomes-2018 }\end{array}$ \\
\hline $\begin{array}{l}\text { 4-may- } \\
20\end{array}$ & $\begin{array}{l}\text { Quédate en casa y juega con anteriores } \\
\text { Doodles populares de Google: Scoville } \\
\text { (2016 }\end{array}$ & $\begin{array}{l}\text { https://www.google.com/Doodles/stay- } \\
\text { and-play-at-home-with-popular-past- } \\
\text { google-Doodles-scoville-2016 }\end{array}$ \\
\hline $\begin{array}{l}5 \text {-may- } \\
20\end{array}$ & $\begin{array}{l}\text { Quédate en casa y juega con anteriores } \\
\text { Doodles populares de Google: Lotería } \\
\text { (2019) }\end{array}$ & $\begin{array}{l}\text { https://www.google.com/Doodles/stay- } \\
\text { and-play-at-home-with-popular-past- } \\
\text { google-Doodles-loteria-2019 }\end{array}$ \\
\hline $\begin{array}{l}\text { 6-may- } \\
20\end{array}$ & $\begin{array}{l}\text { Quédate en casa y juega con anteriores } \\
\text { Doodles populares de Google: } \\
\text { Halloween (2016) }\end{array}$ & $\begin{array}{l}\text { https://www.google.com/Doodles/stay- } \\
\text { and-play-at-home-with-popular-past- } \\
\text { google-Doodles-halloween-2016 }\end{array}$ \\
\hline $\begin{array}{l}7 \text {-may- } \\
20\end{array}$ & $\begin{array}{l}\text { Quédate en casa y juega con anteriores } \\
\text { Doodles populares de Google: Hip } \\
\text { Hop (2017) }\end{array}$ & $\begin{array}{l}\text { https://www.google.com/Doodles/stay- } \\
\text { and-play-at-home-with-popular-past- } \\
\text { google-Doodles-hip-hop-2017 }\end{array}$ \\
\hline
\end{tabular}


Berlanga-Fernández, I. y Sánchez-Esparza, M.

La representación de la pandemia del COVID-19 en los Doodles de Google

\begin{tabular}{|l|l|l|}
\hline $\begin{array}{l}\text { 8-may- } \\
\mathbf{2 0}\end{array}$ & $\begin{array}{l}\text { Quédate encasa y juega con anteriores } \\
\text { Doodles populares de Google: PAC- } \\
\text { MAN (2010) }\end{array}$ & $\begin{array}{l}\text { https://www.google.com/Doodles/stay- } \\
\text { and-play-at-home-with-popular-past- } \\
\text { google-Doodles-pac-man-2010 }\end{array}$ \\
\hline $\mathbf{5 - a g o - 2 0}$ & $\begin{array}{l}\text { Ponte la mascarilla. Salva vidas } \\
\text { https://www.google.com/Doodles/wear- } \\
\text { a-mask-save-lives-aug-5 }\end{array}$ \\
\hline $\begin{array}{l}\mathbf{1 4 - a g o -} \\
\mathbf{2 0}\end{array}$ & Ponte la mascarilla. Salva vidas & $\begin{array}{l}\text { https://www.google.com/Doodles/wear- } \\
\text { a-mask-save-lives-aug-14 }\end{array}$ \\
\hline
\end{tabular}

Figura 2: Doodles sobre la pandemia publicados durante el confinamiento en España 2020

Fuente: elaboración propia

\subsection{Contenido de los Doodles}

El primer Doodle referido a la pandemia se publica el 20 de marzo de 2020. Se titula "homenaje a Ignaz Semmelweis y al lavado de manos" y es un reconocimiento a este médico húngaro como la primera persona que descubre los beneficios médicos de esta práctica, en concreto en lo que se refiere a la reducción de la transmisión de enfermedades. El 4 de abril se publica un segundo Doodle animado con un consejo imperativo "Quédate en casa. Salva vidas".

Dos días más tarde empieza un bloque de 12 publicaciones, todas a lo largo del mes de abril, en las que cada día se dan las gracias a un sector de la población que ha sido relevante en la lucha contra la pandemia. Comenzando por un "gracias a..." se promueve el reconocimiento a los trabajadores de la sanidad pública y a los investigadores de la comunidad científica, y se continua con los profesionales sanitarios, los trabajadores de los servicios de emergencias, el personal de limpieza y recogida de residuos, los trabajadores del campo y agricultores, los trabajadores de las tiendas de alimentación, los profesionales del transporte público, los profesionales de servicios de paquetería, envíos y entregas, los profesionales del sector alimentario, los docentes y profesionales de guarderías, y quienes colaboran en la lucha contra el coronavirus. Este último Doodle se repetirá dos días más (25 y 26 de abril).

El 27 de abril empieza otro bloque de Doodles, 9 en total, con la recomendación "Quédate en casa y juega con..." seguida del enlace a un anterior Doodle particularmente popular. Es el caso de Programación (2017), Críquet (2017), Fischinger (2017), Rockmore (2016), Gnomos de jardín (2018), Scoville (2016), Lotería (2019), Halloween (2016), Hip Hop (2017) y PAC-MAN (2010).

Se añade a esta muestra un Doodle que se repite dos días del mes de agosto, pasado ya dos meses después de la finalización del confinamiento, que recuerda la necesidad de usar la mascarilla pues "salva vidas".

\subsection{Análisis experiencial}

El análisis de cada una de estas experiencias con la ficha propuesta en la metodología nos muestra tres grupos diferenciados y a la vez homogéneos.

Vivat Academia. Revista de Comunicación. 2021, nº 154, 79-94 
Grupo 1. Comprendería el Doodle que es punto de partida (20 de marzo) y el publicado dos semanas más tarde (4 de abril). Los dos son recomendaciones básicas y necesarias en el comienzo del confinamiento contra un virus en pleno apogeo. Se trata de unos Doodles especialmente didácticos. En el primer caso se enseña, a través de imagen, movimiento, sonido y video, la forma y la duración correctas de lavarse las manos según las directrices de la Organización Mundial de la Salud. Como ampliación ofrece, además de información sobre el personaje protagonista -el doctor Semmelweisun video con más consejos para lavarse las manos y otras recomendaciones sobre la pandemia. A partir de esta publicación se introducirá en la información de cada Doodle un texto que señala cómo a medida que COVID-19 continúa impactando a las comunidades de todo el mundo, desde Google se toman medidas para ayudar a las personas a encontrar la información que necesitan, y se añade una dirección web del blog de Google para tener "más información sobre las últimas formas en que la compañía está respondiendo y cómo sus productos pueden ayudar a las personas a mantenerse conectadas durante este tiempo". Es el Doodle que mayor puntuación consigue entre los que se analizan, 250 y el único que alcanza el máximo nivel en el módulo de sentimientos: a la imagen animada que todos tienen, éste añade sonido y video. Además, llega también a 100 en el módulo de pensamiento pues ciertamente incluye una información rica que aporta un alto nivel de conocimientos nuevos y que despierta mucho interés sobre el tema de la pandemia en un momento en el que el desconocimiento, el desconcierto y estupor sobre el covid es todavía muy elevado.

En el segundo, con la frase "Quédate en casa. Salva vidas" cada una de las letras de Google aparece personificada y en el interior de una vivienda, practicando actividades como la lectura o ejercicios gimnásticos, cantando con un instrumento musical o hablando por teléfono. Aun siendo un Doodle sencillo, sin sonido ni video y con una animación bastante elemental, la información que aporta es muy gráfica y a la vez, útil. La fuerza del texto escrito "quédate en casa. Salva vidas" se refuerza de una forma simpática con la visión de las letras personificadas encerradas en una vivienda que además ofrecen una variedad de ocupaciones que se convertirán en la cotidianeidad de esos meses de confinamiento.

Grupo 2. En este grupo se incluyen las 12 publicaciones del mes de abril que agradecen la labor prestada por sectores de la sociedad que trabajan en primera línea por facilitar servicios primarios al resto de la población. Comienza por el sector sin duda más protagonista y el apreciado de ese momento: los profesionales de la sanidad pública y los investigadores de la comunidad científica. Todos estos Doodles siguen un patrón homogéneo en su apariencia, razón por la que alcanzan los mismos valores en cada uno de los cinco módulos. El esquema sería el siguiente: la primera letra del logotipo de Google está personificada; con un movimiento lanza un corazón que se detiene a mitad del recorrido, y lo continúa hasta llegar a la última letra, también personificada y con algún elemento que la hace reconocible como el sector al que se le envía el agradecimiento: la " $\mathrm{e}$ " es un sanitario, maestro, chef o repartidor, pongamos por caso, que se encuentra en un aula, vehículo, puesto de fruta...etc. Al recibir el corazón da un salto, y por encima de su cabeza salen tres corazones. Este bloque se

Vivat Academia. Revista de Comunicación. 2021, nº 154, 79-94 
cierra con un Doodle que se dedica en general a todos aquellos que de alguna forma han colaborado en la lucha contra el covid, y recoge imágenes de todos estos sectores.

Cada uno de estos Doodles tiene un nivel bajo en los módulos se sentimientos, actuación y relación, y medio alto en el módulo de pensamiento: se sigue incluyendo información sobre el covid y sobre el desarrollo del momento delicado que se está viviendo. Así, las peculiaridades del contexto hacen que el interés que pueda suscitar esta información sea elevado.

Grupo 3. Lo constituye los nueve Doodles que recomiendan permanecer en casa con la sugerencia de jugar con uno de los Doodles anteriores más interactivos y entretenidos. Es una estrategia muy inteligente por parte de la marca. Subraya reiteradamente la medida obligada por las autoridades de permanecer en el domicilio familiar, pero lo acompaña con la aportación de un juego. Si bien este grupo, al igual que el anterior reúne un nivel bajo en los módulos se sentimientos, actuación y relación, llega al máximo nivel en el módulo de pensamiento: a la información incluida sobre el covid se le añade toda la que se proporciona en el enlace que remite al juego sugerido. Cada uno de estos juegos son auténticas experiencias holísticas que incluyen un alto grado de animación, músicas pegadizas, y enormes posibilidades de actuación, creación y compartición.

Como apuntamos más arriba, en el mes de agosto se publica durante dos días ( 5 y 14 de agosto) un Doodle con referencia directa a la pandemia. Se trata de una animación de las letras del logo oficial de Doodle que se cubren con diferentes mascarillas; al cabo de unos segundos las letras se separan entre ellas. De esta forme Google recordaba de forma gráfica dos de las medidas más importantes en esta pandemia, el uso de mascarilla y el cuidado de la distancia de seguridad, y lo hace en un momento álgido de las vacaciones de verano, donde ya se dejaba sentir las consecuencias de la relajación de la población. El nivel de cada uno de los módulos experienciales de este Doodle sigue la misma línea que los del grupo 3 y por tanto coincide en el dato numérico otorgado a cada módulo. 
Berlanga-Fernández, I. y Sánchez-Esparza, M.

La representación de la pandemia del COVID-19 en los Doodles de Google

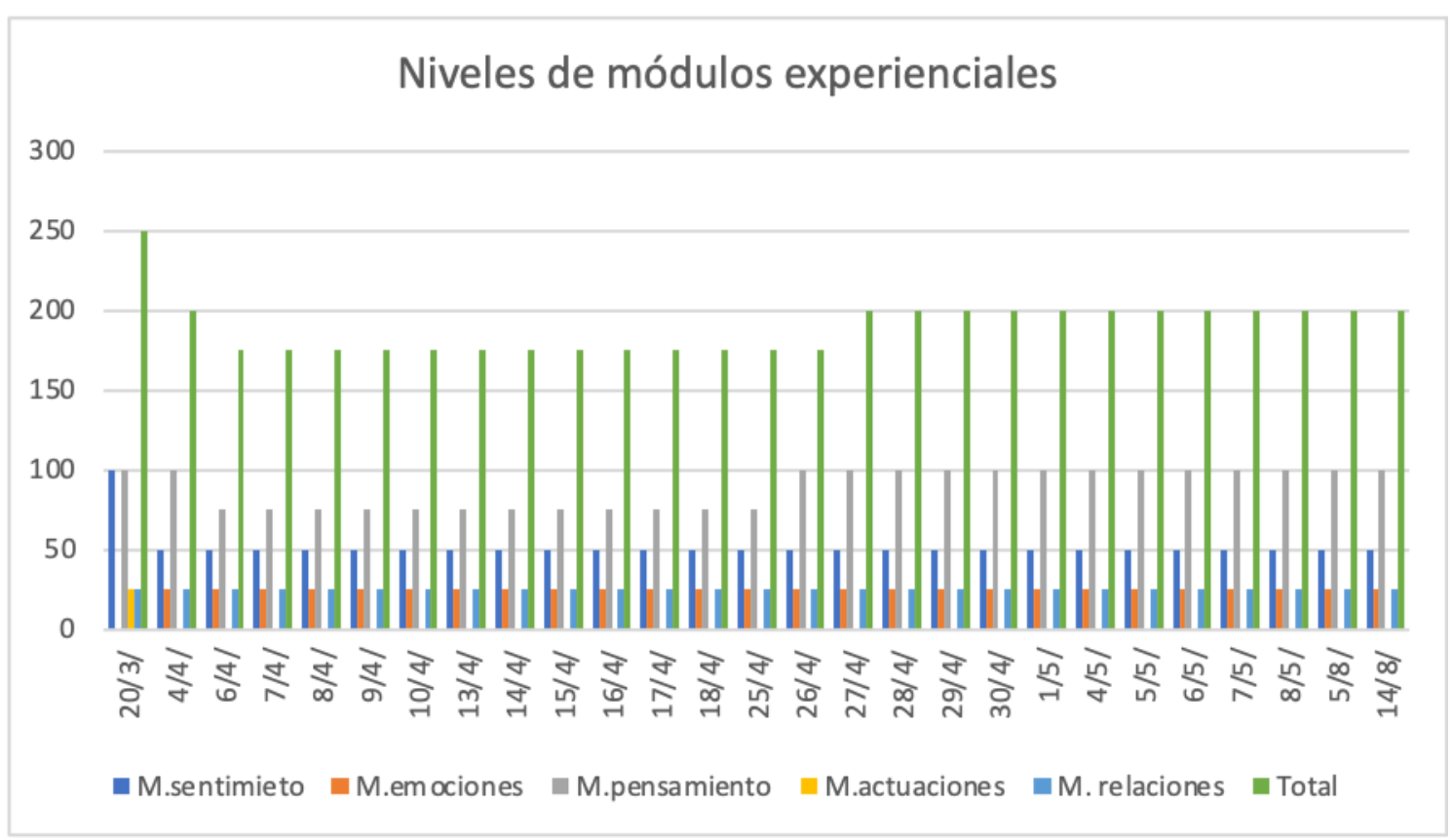

Figura 3: Niveles de módulos experienciales

Fuente: elaboración propia

\subsection{Informar, enseñar, entretener}

Esta compañía internacional que empezó siendo un buscador se ha convertido ya en el mayor medio de comunicación mundial (ZenithOptimedia, 2015). Las circunstancias excepcionales y el contexto mundial que originan los Doodles analizados ponen de manifiesto que Google, de una forma muy patente, hace suyas las funciones que tradicionalmente se han atribuido a los medios de comunicación: informar, formar y entretener. En este caso, la publicidad o la misma información publicada para predisponer a la población a la demanda del producto no parece que sea la primera función que Google persiga. Téngase en cuenta que el Módulo de emociones mediante el recurso a las figuras retóricas tiene la opción de estimular determinadas emociones y afectividades hacia la marca, y en los casos analizados se ha mantenido en un nivel medio-bajo.

Sin embargo, las funciones de información, formación y entretenimiento están ampliamente justificadas y representadas en todos y cada uno de los Doodles analizados. Se aprecia una voluntad de servicio a la población que facilita el aprendizaje y mejor conocimiento de la realidad del momento, proporcionando información actual y datos sobre el covid-19. También Google adopta en esta ocasión una tarea formativa. Nos referimos a la intención de concienciar, sensibilizar y en consecuencia mover a acciones concretas (quedarse en casa, usar mascarilla...) que se aprecia en cada Doodle. Y siendo fiel a su origen, a pesar de lo dramático de la situación, se proporciona un espacio de diversión. Recuérdese que, según los creadores del logotipo animado, se persigue que el usuario juegue con la marca. 


\section{DISCUSIÓN Y CONCLUSIONES}

Podemos concluir que los Doodles de Google publicados durante el confinamiento que sufrió la población española y gran parte del planeta y que se refieren al covid-19, son híbridos experienciales que han combinado varios módulos experienciales. Esta experiencia ha sido proporcionada especialmente por las imágenes, los textos, las animaciones y las herramientas para ampliar información; y en menos medida los sonidos, las herramientas de interactuación, de compartición y herramientas de intercambio de información o producción colectiva.

La sistematización de los módulos experienciales llevada a cabo a través de un dato numérico revela que, en general, los Módulos de sensaciones y de sentimientos han proporcionado una estimulación baja: solo un Doodle ha incorporado sonido a sus imágenes en movimiento; a su vez, la presencia de figuras retóricas en ningún caso ha superado las 10 por Doodle. Igualmente, los Módulos de actuaciones y de relaciones, esto es, la capacidad de interaccionar, de generar conexiones con otras personas y realizar un producto final de forma colectiva, ha estado muy por debajo de lo que se alcanza en otros Doodles. Ha destacado, sin embargo, el Módulo de pensamiento. En primer lugar, por la elevada cantidad y constante información ofrecida sobre la pandemia, pero también por la capacidad para aportar conocimiento e intrigar con los juegos sugeridos que acompañaban al enunciado "quédate en casa". Se ha conseguido así apelar al intelecto y generar vivencias cognitivas basadas en el aprendizaje, la resolución de problemas o la creatividad.

Estos resultados nos revelan que la estrategia de marca se ha enfocado en dos direcciones: en primera instancia, una voluntad de concienciar a la ciudadanía en esta situación tan límite que se atravesaba en esas fechas y que aun vive el Planeta; y en segundo lugar el deseo de mostrar agradecimiento a determinados sectores de la población que han estado trabajando en primera línea por los demás, tantas veces de una forma heroica y desinteresada. Estas circunstancias muestran que, a pesar de simplificarse la intensidad de la estimulación sensorial de los Doodles con respecto a otros momentos quizás menos trascendentes para los usuarios, la estrategia de los Doodles responde al marketing experiencial, pues son acciones experienciales donde se comparten sentimientos, sensaciones, pensamientos y actuaciones con la audiencia, y que además se hace de forma pedagógica, lúdica y emotiva.

\section{REFERENCIAS}

Atwal, G. \& Williams, A. (2009). Luxury brand marketing-The experience is everything! Journal of Brand Management, 16, 338-346. https://doi.org/10.1057/bm.2008.48

Berlanga, I., Galmés, M. \& Repiso, R. (2016). Propuesta de un método para analizar el diseño de comunicaciones experienciales de marca en entornos digitales. En 
VV.AA. (coords.). Antología de investigación sobre educación personal branding e innovación social. Universidad Autónoma de Nueva León.

Cobos, T. L. (2018). Las percepciones y experiencias sobre Google News de los editores de medios noticiosos latinoamericanos indexados en las ediciones de Colombia y México. Estudios Sobre El Mensaje Periodístico, 24(2), 1183-1198. https://doi.org/10.5209/ESMP.62208

Coll Rubio, P. \& Micó, J. L. (2019). La planificación estratégica de la comunicación en la era digital. Los casos de estudio de Wallapop, Wetswing y Fotocasa. [Communication strategies in the new economy: the case studies of Wallapop, Westwing and Fotocasa]. Vivat Academia. Revista de Comunicación, 147, 125-138. http://www.vivatacademia.net/index.php/vivat/article/view/1147

DW Español (11 de abril de 2012). El fenómeno Google-Doodle [Vídeo] https://www.youtube.com/watch?v=Y5iZjlclkJc

Gil, M., Gómez de Travesedo, R. \& Almansa, A. (2020). YouTube y coronavirus: análisis del consumo de vídeos sobre la pandemia COVID-19. Revista Latina de Comunicación Social, 78, 121-153. https:// www.doi.org/10.4185/RLCS-2020-1471

Hetzs, M. (10 de agosto de 2012). Inside Google [Vídeo] https://www.youtube.com/watch?v=B51LGupOLag

Lenderman, M. (2006). Are you experiential? Marketing, 111(5), 11. http://www.espaciotv.es:2048/referer/secretcode/trade-journals/are-youexperiential/docview / $227213060 /$ se-2?accountid $=142712$

Medina, R. \& Quispe, J. (2019). Acercamiento teórico al marketing sensorial: sentidos, experiencias de marcas y modelos. 593 Digital Publisher CEIT, 4(3), 4-16. https://doi.org/10.33386/593dp.2019.3.82

Montaña-Blasco, M., Ollé-Castellà, C. \& Lavilla-Raso, M. (2020). Impacto de la pandemia de Covid-19 en el consumo de medios en España. Revista Latina de Comunicación Social, 78, 155-167. https://doi.org/10.4185/RLCS-2020-1472

Romero, D. E., San Román, D. J., A. Ruiz \& Oceja, D. J. (2018). La percepción de los/as periodistas sobre la comunicación organizacional: el caso de Google. Prisma Social, (22), 37-60. http://www.espaciotv.es:2048/referer/secretcode/scholarlyjournals/la-percepción-de-los-as-periodistas-sobre/docview/2190928804/se-

2?accountid $=142712$

Singhal, S. \& Khare, K. (2017). Does Sense Reacts For Marketing - Sensory Marketing. International Journal of Management, 5(5), 1-18. https://papers.ssrn.com/sol3/papers.cfm?abstract_id=2956779 
Schmitt, B. (2010). Experiential marketing: A new framework for design and communications. Design Management Journal (Former Series), 10(2), 10-16. https://doi.org/10.1111/j.1948-7169.1999.tb00247.x

Schmitt, B. (2006). Experiential marketing. Ediciones Deusto.

Schmitt, B., Brakus, J. J. \& Zarantonello, L. (2015). From experiential psychology to consumer experience. Journal of Consumer Psychology, 25(1), 166-171.

Vise, D. \& Malseed, M. (2006). La historia de Google: los secretos del mayor éxito empresarial, mediático y tecnológico de nuestro tiempo. La Esfera de los Libros.

Zenith Optimedia (2015). Google strengthens its position as world's largest media owner. https://www.zenithmedia.com/google-strengthens-position-worlds-largestmedia-owner/

\section{AUTOR/ES:}

\section{Inmaculada Berlanga Fernández}

Doctora en Filología y en Comunicación Audiovisual. Profesora Titular acreditada por la CNEAI en la Universidad Internacional de la Rioja (Nivel I). Dos sexenios de investigación. Visiting Professor en Università Cattolica del Sacro Cuore, Milano. Investigadora Principal de PROCOMM (Prospectivas en Comunicación Multimedia) de UnirResearch. Miembro del Grupo Comunicar y de la red internacional Alfamed.

Orcid ID: https:/ / orcid.org/0000-0002-0135-624X

Google Scholar: https://scholar.google.es/citations?user=9D7D9W4AAAAJ\&hl=es

Web of Science Researcher ID: L-9117-2019

\section{Marta Sánchez Esparza}

Doctora en Comunicación. Profesora asociada en la Universidad Rey Juan Carlos. PDI en EAE Business School (Grupo Planeta). Investigadora de PROCOMM (Prospectivas en Comunicación Multimedia) de UnirResearch.

Orcid ID: https:// orcid.org/0000-0001-6525-0148

Google Scholar: https://scholar.google.es/citations?hl=es\&user=f348CnoAAAAJ 